\title{
Ground Handling Performance Based Clustering for Vietnam Airlines Strategic Management
}

\author{
Tien-Chin Wang ${ }^{1}$, Yen Thi Hong Pham ${ }^{1,2,{ }^{*} \text {, Huong Thi Mai Truong }}{ }^{3}$ \\ ${ }^{1}$ Department of International Business, National Kaohsiung University of Science and Technology, Kaohsiung, Taiwan \\ ${ }^{2}$ Department of Business English, Foreign Trade University, Hanoi, Vietnam \\ ${ }^{3}$ School of Global, Urban and Social Studies, The Royal Melbourne Institute of Technology, Melbourne, Australia
}

Email address:

tcwang@kuas.edu.tw (Tien-Chin W.), yensasa@gmail.com (Yen T. H. P.), huongthimai.truong@rmit.edu.au (Huong T. M. T.)

${ }^{*}$ Corresponding author

\section{To cite this article:}

Tien-Chin Wang, Yen Thi Hong Pham, Huong Thi Mai Truong. Ground Handling Performance Based Clustering for Vietnam Airlines Strategic Management. International Journal of Business and Economics Research. Vol. 7, No. 3, 2018, pp. 55-61. doi: $10.11648 /$ j.ijber.20180703.12

Received: May 10, 2018; Accepted: July 9, 2018; Published: July 19, 2018

\begin{abstract}
Vietnam Airlines (VNA) can add more value to its offerings to pursue differentiation strategy as a competitive advantage by maximizing effectiveness of the ground handling service network it hires. This paper aims at making recommendation to VNA on using a set of managerial tools to monitor and continuously improve its service network being operated at 29 international airports. The tools include cluster analysis, ANOVA and Scheffé post hoc to assist the top managers (1) to have an overview of VNA ground handling service quality at world-wide airports by monitoring the performance of airport clusters instead of an individual airport; (2) to clearly observe its effective and ineffective airport clusters on every certain criterion. With this set, the management board can decide strategic management for ground handling service not only to be more effective and more feasible but also to be in line with marketing strategy to differentiate its offerings to excel in the fierce air industry competition.
\end{abstract}

Keywords: Cluster Analysis, Performance, Ground Handling, Service Quality, Vietnam Airlines

\section{Introduction}

In recent years, Vietnam Airlines (VNA), Vietnam's national carrier, has been experiencing fierce competition on both domestic and international markets. As opportunities for further domestic development are becoming more limited due to rapidly expanding local competitors and market saturation, the company has concentrated more on international market expansion. One of the aspects that the airline has focused on lately is improving the quality of its services to international passengers. These services include ticket reservation, purchase, airport ground services and onboard services. Among these, ground services are of significant importance. In order to regulate ground handling being provided, VNA signs a service level agreement (SLA) with a ground handling company at the international airport that it works with. For each ground handling company, one VNA expatriate station manager is assigned to supervise the service quality.

The SLA establishes mutually agreed standards and targets used to monitor the performance of the ground handling companies. Evaluation of the performance against the service standards and targets is carried out during meetings between VNA and the handling company. They normally cover the following:

1. Punctuality: For example, the number of flight delays within 15 minutes of estimated time of departure must be more than $99.5 \%$. This refers only to flight delays attributable to the handling company.

2. Check-in process: This includes transit passengers handling, queuing area order, professional staff at check-in, and if required, assisting passengers in doing airport procedures.

3. Boarding process covers the clearness, coherency of 
speech for boarding and lounge to aircraft convenience

4. Staff manners and attitude

5. Customer complaints

6. Baggage mishandling, and

7. Personal documents mishandling.

Although a SLA serves as mutually agreed standards and targets for airport ground services, it does not ensure that passenger's demands are met satisfactorily. To assess the service quality and the level of customer satisfaction, VNA undertakes regular passenger surveys to collect their feedback. In addition, records relating to airport ground services are maintained by machines and staff from the airline's Market Service Department. Data collected from these sources are consolidated annually. The consolidated data are then compared with the agreed standards and targets for the airport. The outcomes of the comparison are used to determine whether the ground handling services of a particular airport are up to standards or not.

Up to present, VNA uses the SLA as the set of service standards or targets against which the performance results of the respective ground handling company are checked. If the performance results are the same or higher than the targets, then the carrier concludes that the handling company meets the criteria and it services are up to standard. Apart from this conclusion, little can be learned from the passenger surveys and recorded data.

The remaining of this paper is organized as follows: Section 2 explains what cluster analysis is, its benefits and application. Section 3 introduces our research method, and section 4 describes and discusses the findings of the study. Finally, in section 5 the authors offer some conclusions.

\section{Literature Review}

\subsection{Airport Classification with Cluster Analysis}

Cluster analysis or clustering is a method involved in classifying a set of observations into subsets, which are called clusters so that observations in the same cluster are similar in some sense. Two types of cluster analysis including hierarchical clustering and k-mean cluster are commonly used in classifying airports, although one of the key benefits of hierarchical clustering over the other is stressed by Rodríguez-Déniz et al. is the illustration of a tree-like diagram (i.e. dendrogram) [1]. With the dendrogram graphic, hierarchical classification can provide a typical structure which is more informative than the flat clusters gained from $\mathrm{k}$-means. The dendrogram is a convenient visual aid to exhibit a hierarchical sequence of clustering assignments. It is in the form of a simple tree where each node indicates a cluster. Each cluster represents a single data point and the root node is the cluster consisting of the whole data set. Therefore, major scholars have grouped airports in their airport research, using hierarchical clustering (eg. [1-5]). Moreover, Ward's method is frequently used with cluster analyses [2, 5-8]. Hands \& Everitt claims this method is more complicated but more accurate on results and minimal on variance between objects [9]. In term of distance measure, Euclidean distance is the most commonly used measure [10] and recommended when using Ward's method.

\subsection{Service Quality in Airline Industry}

It has been realized that delivering superior service quality can be of key importance for success and survival in today's competitive business environment. Hill et al. highlight that super quality can help a company differentiate its products and charge a premium price to improve its profitability [11]. Apart from that, The IATA Corporate Air Travel Survey 1997 undertakes research in North America, Europe and Asia and demonstrates the different views of passengers [12]. In this case, passengers assessed punctuality ( 65 per cent) to be the first concern followed by scheduling ( 52 per cent) and price (37 per cent). This does not mean price is less important to airlines but compared with price, service quality is found to be a stronger determinant of satisfaction [13]. By offering superior service, companies are able to charge 8 per cent more for their product [14] while gaining market share growth [15] and profitability. It is also noticed that airlines still can make a profit when reducing passenger defection rate. Thus, carriers should develop a service strategy "improving service quality is improving the profitability".

In airline industry, carriers have made a lot of efforts to improve service quality with the aim at satisfying passengers, meeting customer expectations to maximize profitability in a long run. Therefore, empirical research supports that service quality is perceived and assessed by customers (e.g. [16-27]). Additionally, the main criteria and the sub-criteria used to measure service quality in air service industry are multiple [20, 28-30, 23, 31-35]. However, they include all criteria which VNA used to measure the service quality (on-time performance, check-in process, boarding process, staff attitude, customer complaints, baggage handling, and personnel document mishandling) being provided by the handdling companies at 29 international airports.

\section{Method}

\subsection{Sample Characteristics}

The data for this research have been collected from quarterly SLA performance reports of ground handling companies at VNA's 29 international airports. VNA's Market Service Department have developed seven criteria to assess the performance of these companies. They are criterion 1 check-in process; criterion 2 - boarding process; criterion 3 staff attitude; criterion 4 - customer complaint; criterion 5 baggage mishandling; criterion 6 - personal document; and criteria 7 - punctuality. However, in this study, only the data of the first six criteria have been used. The criterion punctuality has been excluded because almost all of these airports have been on time.

The figures for these criteria are calculated in terms of a 100 -score scale. On the first three criteria, the total scores for each criterion were for the effectiveness of the ground 
handling companies, whereas on the last three criteria, the total scores for each criterion were for their ineffectiveness. From the quarterly figures, the authors decided to form one set of data for the year 2016 as VNA officially ranks the effectiveness of its ground handling service performance on yearly basis.

\subsection{Application of Cluster Analysis and ANOVA and Scheffé Post Hoc}

In this study, cluster analysis with Ward's method and Euclidean distance, ANOVA and Scheffé post hoc test have been used to analyse the data. The aim of this is to observe the performance of an airport cluster or a group of airports, instead of an individual airport. Therefore, first, cluster analysis with Ward's method and Euclidean distance was applied to classify 29 international airports into clusters with regard to the six ground handling service quality performance criteria. Ward's method has been trialed with different distances, but only with Euclidean distance, the dendrograms presents the clearest graphics of clusters and the number of clusters was five. Second, ANOVA was used to determine where the significant differences were for these criteria. As a result of using ANOVA, a number of underperforming clusters have been identified for each criterion. Third, Scheffé post hoc test was applied on criteria for which significant differences have been recorded among groups of handling companies. As the result of Scheffé, both of outperformed clusters and underperformed clusters are identified.

\section{Research Findings and Discussion}

\subsection{Classified Airports of 2016 SLA Data}

As mentioned previously, cluster analysis was employed to group airports with regards to their six ground handling service quality criteria. Additionally, Ward's method was chosen as the applied agglomerative algorithm using Euclidean distance as distance measurement. Airports grouped in a cluster were the airports having performed similar ground handling service quality. Although in Figure 1 , cluster analysis results revealed numerous clusters of 29 airports at different distances, the authors decided to make a cutting on the dendrogram at the distance 12 for the year to gain five clusters. Therefore, the 29 airports have been labelled as follows:

Cluster 1: FUK; KIX; NGO; RGN (4)

Cluster 2: CGK; SYD; VTE (3)

Cluster 3: CAN; CDG; ICN; KUL; NRT; PNH; PUS (7)

Cluster 4: LPQ; LHR (2)

Cluster 5: BKK; DME; PEK; PVG; REP; SIN; TPE; CTU; FRA; HKG; HND; KHH; MEL (13)

However, the dendrogram graphic indicated that CDG has always been isolated from the others. It could not become a member of any clusters. This is because it has relatively poor performance of baggage handling. Finally, CDG is included in the cluster 3 whose mean scores was the closest to it, aiming at reasonably applying ANOVA next step. Cluster 4 is the smallest with two airports but cluster 5 is the biggest with 13 airports.

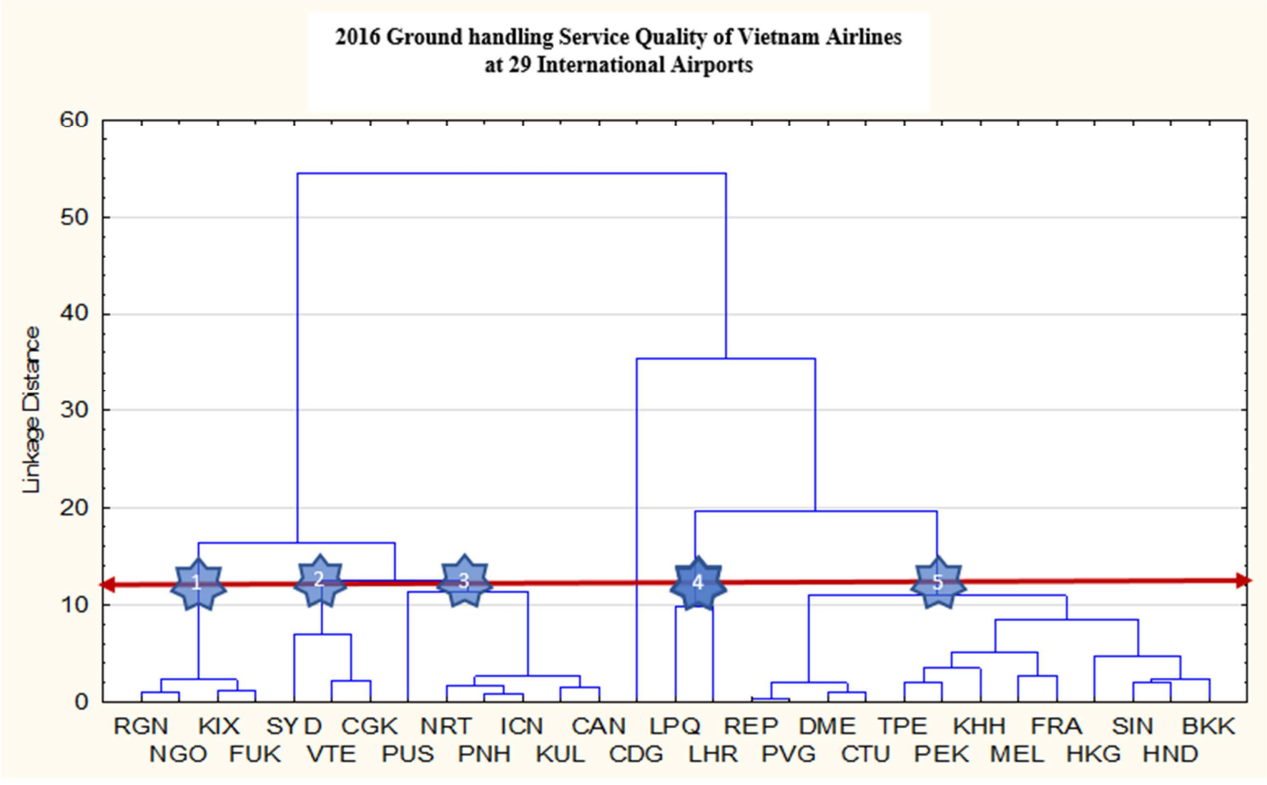

Figure 1. Dendrogram graphic 2-2016 SLA data.

\subsection{ANOVA Results of SLA 2016}

The ANOVA results indicated that there have been nonsignificant differences for three criteria and statistically significant differences for the three remaining criteria. The non-significant differences lay on criterion $4 \quad(\mathrm{~F}=0.792$, $\mathrm{p}=0.542)$, criterion $5(\mathrm{~F}=0.760, \mathrm{p}=0.562)$, criterion $6(\mathrm{~F}=1.689$, $\mathrm{p}=0.185$ ) at an alpha level of $5 \%$ as shown in Table 1 . The outcomes showed that for passenger complaints, baggage mishandling and personal documents mishandling, the scores attained were statistically equal so the performance of these five clusters of 29 airports has been satisfactory. Unlikely, the 
statistical significances differ in criterion $1 \quad(\mathrm{~F}=22.674$, $\mathrm{p}<0.001)$, criterion $2 \quad(\mathrm{~F}=24.075, \quad \mathrm{p}<0.001)$, criterion 3 $(\mathrm{F}=14.620, \mathrm{p}<0.001)$ at $1 \%$ alpha level as shown in Table 1. The scores for check-in process, boarding process, and staff attitude have been at relatively different levels. These three criteria have not been equally well-performed by the five clusters so there existed significant differences between the clusters. Since all underperformed tasks have been discovered and allocated, it is managerially believed that it was these criteria which needed scrutinizing and improving.

In theory, ANOVA will define for which criteria there is statistically significant difference of at least one pair of clusters, but does not indicate where the differences are [16]. Therefore, the authors continued to use Scheffé post hoc test to figure out actual poorly performing clusters in the next part [36].

Table 1. ANOVA results of 2016 data.

\begin{tabular}{|c|c|c|c|c|c|c|}
\hline & & Sum of Squares & df & Mean Square & $\mathbf{F}$ & Sig. \\
\hline CRI_1 & Between Groups & 198.629 & 4 & 49.657 & 22.674 & $.000 * * *$ \\
\hline \multirow[t]{2}{*}{ Check-in process } & Within Groups & 52.562 & 24 & 2.190 & & \\
\hline & Total & 251.191 & 28 & & & \\
\hline CRI_2 & Between Groups & 198.992 & 4 & 49.748 & 24.075 & $.000 * * *$ \\
\hline \multirow[t]{2}{*}{ Boarding process } & Within Groups & 49.593 & 24 & 2.066 & & \\
\hline & Total & 248.584 & 28 & & & \\
\hline CRI_3 & Between Groups & 131.932 & 4 & 32.983 & 14.620 & $.000 * * *$ \\
\hline Staff attitude & Total & 186.077 & 28 & & & \\
\hline CRI_4 & Between Groups & 5.874 & 4 & 1.469 & .792 & .542 \\
\hline \multirow[t]{2}{*}{ Passenger complaint } & Within Groups & 44.486 & 24 & 1.854 & & \\
\hline & Total & 50.360 & 28 & & & \\
\hline CRI_5 & Between Groups & 64.266 & 4 & 16.066 & .760 & .562 \\
\hline \multirow[t]{2}{*}{ Baggage mishandling } & Within Groups & 507.676 & 24 & 21.153 & & \\
\hline & Total & 571.941 & 28 & & & \\
\hline CRI_6 & Between Groups & 1.481 & 4 & .370 & 1.689 & .185 \\
\hline Personal document mishandling & Total & 6.742 & 28 & & & \\
\hline
\end{tabular}

$* * *$ : denotes $\mathrm{p}<0.001$

\subsection{Scheffé Post Hoc Results of 2016 SLA}

Scheffé post hoc has been employed for criterion 1, criterion 2 and criterion 3, which were identified by ANOVA to be criteria with statistically significant differences, to figure out how each cluster actually performed the ground handling service quality for each criterion. The test has determined pairs of clusters having significant differences in performance as well as pairs of clusters performing the criterion equally in deed. Therefore, the ranking of performance of the five clusters for these criteria was able to be revealed precisely.

As showed in table 2, for criterion 1, Scheffé post hoc results presents that cluster $5(81.8708)$ and cluster 2 (82.4333) has greater mean value than cluster 1 (76.7875). Similarly, cluster $4(88.2200)$ has greater mean value than Cluster 2 (82.4333), Cluster 5 (81.8708), Cluster 3 (79.9029), and Cluster 1 (76.7875). Cluster 4 is the biggest (88.2200) whereas Cluster 1 (76.7875) is the smallest. The comparisons of five-cluster mean values suggested that there are significant gaps of performance among cluster 5 , cluster 2 and cluster 1; between cluster 4 and one of the other clusters. However, the performance of cluster 3 , cluster 5 and cluster 2 is equal. The results also have indicated that cluster 1 carries out the task of check-in process least effectively whereas cluster 4 does most effectively. For the ranking top down of check-in process based on the Scheffé test is as follows: cluster 4 has a leading performance followed up by cluster 3 , cluster 5 and cluster 2 , but the cluster 1 has the poorest performance.

Likewise, for criteria 2, the mean value of cluster 3 (79.0100) is greater than that of cluster 2 (74.8767), suggesting that the performance distance between cluster 3 and cluster 2 is statistically significant. Cluster 5 (81.5338) also has greater mean value than cluster 1 (75.9900) and cluster 2 (74.8767) while cluster $4(83.4000)$ has greater mean value than cluster 3 (79.0100), cluster 1 (75.9900) and cluster 2 (74.8767). These outcomes define that cluster 5 performs better than cluster 1 and cluster 2; cluster 4 also performs better than cluster 3 , cluster 1 and cluster 2 . In addition, cluster $4(83.4000)$ which has the biggest mean value is the best performing cluster whereas cluster 2 (74.8767) which has the smallest mean value is the poorest performing cluster.

For criteria 3, there appears significantly unequal mean values between some pairs like cluster 5 (82.2546) and cluster 1 (77.3475); cluster 4 (86.2000) and cluster 2 (80.8300); cluster 3 (80.1514) and cluster 5 (82.2546). This has suggested that the performance gaps between these pairs are actually significant. Additionally, cluster 4 (86.2000) mean value is the biggest whereas cluster $1(77.3475)$ is the smallest, indicating that cluster 4 is the best while cluster 1 is the worst. 
Table 2. Scheffé post hoc Results - Comparisons of Airport Clusters.

\begin{tabular}{|c|c|c|c|c|c|c|}
\hline & \multirow{2}{*}{ CLUSTER } & \multirow{2}{*}{$\mathbf{N}$} & \multicolumn{2}{|c|}{ Subset for alpha $=0.05$} & \multirow[b]{2}{*}{3} & \multirow[b]{2}{*}{4} \\
\hline & & & 1 & 2 & & \\
\hline \multirow{6}{*}{$\begin{array}{l}\text { CRI_1 } \\
\text { Check-in process }\end{array}$} & 1 & 4 & 76.7875 & & & \\
\hline & 3 & 7 & 79.9029 & 79.9029 & & \\
\hline & 5 & 13 & & 81.8708 & & \\
\hline & 2 & 3 & & 82.4333 & & \\
\hline & 4 & 2 & & & 88.2200 & \\
\hline & Sig. & & 109 & .263 & 1.000 & \\
\hline \multirow{6}{*}{$\begin{array}{l}\text { CRI_2 } \\
\text { Boarding process }\end{array}$} & 2 & 3 & 74.8767 & & & \\
\hline & 1 & 4 & 75.9900 & 75.9900 & & \\
\hline & 3 & 7 & & 79.0100 & 79.0100 & \\
\hline & 5 & 13 & & & 81.5338 & 81.5338 \\
\hline & 4 & 2 & & & & 83.4000 \\
\hline & Sig. & & .883 & .110 & .240 & .532 \\
\hline \multirow{6}{*}{$\begin{array}{l}\text { CRI_3 } \\
\text { Staff attitude }\end{array}$} & 1 & 4 & 77.3475 & & & \\
\hline & 3 & 7 & 80.1514 & 80.1514 & & \\
\hline & 2 & 3 & 80.8300 & 80.8300 & & \\
\hline & 5 & 13 & & 82.2546 & & \\
\hline & 4 & 2 & & & 86.2000 & \\
\hline & Sig. & & .063 & .458 & 1.000 & \\
\hline \multirow{6}{*}{$\begin{array}{l}\text { CRI_4 } \\
\text { Passenger complaint }\end{array}$} & 3 & 7 & 98.9157 & & & \\
\hline & 4 & 2 & 99.8900 & & & \\
\hline & 1 & 4 & 99.9200 & & & \\
\hline & 2 & 3 & 99.9267 & & & \\
\hline & 5 & 13 & 99.9977 & & & \\
\hline & Sig. & & .873 & & & \\
\hline \multirow{6}{*}{$\begin{array}{l}\text { CRI_5 } \\
\text { Baggage mishandling }\end{array}$} & 4 & 2 & 94.9000 & & & \\
\hline & 3 & 7 & 95.9357 & & & \\
\hline & 5 & 13 & 98.2762 & & & \\
\hline & 2 & 3 & 98.9567 & & & \\
\hline & 1 & 4 & 99.8125 & & & \\
\hline & Sig. & & .703 & & & \\
\hline \multirow{6}{*}{$\begin{array}{l}\text { CRI_6 } \\
\text { Personal document mishandling }\end{array}$} & 4 & 2 & 98.9850 & & & \\
\hline & 2 & 3 & 99.1833 & & & \\
\hline & 3 & 7 & 99.5057 & & & \\
\hline & 5 & 13 & 99.6754 & & & \\
\hline & 1 & 4 & 99.7850 & & & \\
\hline & Sig. & & 264 & & & \\
\hline
\end{tabular}

\section{Conclusion}

The tools including cluster analysis, ANOVA and Scheffé post hoc offered by this research to VNA to measure ground handling performance are useful and beneficial. Cluster analysis presents a dendrogram to allow top managers to have a picture of the ground handling service performance. The picture shows some airports with similar performance can be grouped together to form a cluster. Five clusters were selected for this study. They possess two characteristics: (1) The airports in each cluster have the high degree of similarity for the criteria based on which the cluster has been formed, (2) These airport clusters are relatively distinct. Using cluster analysis to group 29 airports into five airport clusters creates a general image to understand the performance of the whole ground handling system, which is better than evaluating the system by looking at a single airport. After that the application of ANOVA was to get an overview of the performance of the whole service system which is of even more importance. The test assists top managers to learn that five clusters have functioned satisfactorily in terms of some criteria but they have not for the others. This paper has pointed out three criteria with unsatisfactory performance. They consist of criterion 1 , criterion 2 and criterion 3 . Therefore, with ANOVA the weaknesses of the ground handling service system were specified. Additionally, once the criteria with unsatisfactory performances are identified, Scheffé post hoc test is employed to figure out which clusters actually performed ineffectively. This test is a good choice for the purpose of comparing when complex comparisons are being made. Hence, according to its results, the level of real differences in performance of five clusters were wellunderstood. Interestingly, they could be recognized as clusters with significantly different performances or ones with real equal performances although their scores always vary. Importantly, senior managers can consider these outcomes to take a course of action for certain clusters with poor performances to strengthen VNA's international ground handling service system.

Analysing performance of clusters of airport with respect to the six criteria is critical to VNA's course of improving their service quality as it can identify and take action to enhance underperformed clusters as well as maintain those with excellent outcomes. Moreover, with this management mechanism, it is believed that VNA can implement a 
strategic management, which is to corporate management strategy with marketing strategy, to differentiate its offerings to excel in the fierce air industry competition.

\section{Acknowledgements}

We would like to thank National Kaohsiung University of Science and Technology for their support. We also want to extend our special thanks to Mr. Nguyen T. C., the station manager of VNA Kaohsiung Airport Office, for providing input for many of our ideas.

\section{References}

[1] H. Rodríguez-Déniz, P. Suau-Sanchez, and A. Voltes-Dorta, "Classifying airports according to their hub dimensions: an application to the US domestic network," Journal of Transport Geography, 33, pp. 188-195, 2013.

[2] P. Malighetti, S. Paleari, R. Redondi, "Airport classification and functionality within the European network," Problem Perspective Management 7/1, 183-196, 2009.

[3] R. Mayer, "Airport classification based on cargo characteristics," Journal of Transport Geography, 54, pp. 5365, 2016.

[4] J. Sarkis, and S. Talluri, "Performance based clustering for benchmarking of US airports," Transportation Research Part A: Policy and Practice, 38 (5), pp. 329-346, 2004.

[5] H. A. Vogel and A. Graham, "Devising airport groupings for financial benchmarking," Journal of Air Transport Management, 30, pp. 32-38, 2013.

[6] J. Anable, “'Complacent car addicts' or 'aspiring environmentalists'? Identifying travel behaviour segments using attitude theory,". Transport Policy, 12 (1), pp. 65-78, 2005 .

[7] L. Davison, and T. Ryley, "Tourism destination preferences of low-cost airline users in the East Midlands," Journal of Transport Geography, 18 (3), pp. 458-465, 2010.

[8] E. Martinez-Garcia, and M. Royo-Vela, "Segmentation of low-cost flights users at secondary airports," Journal of Air Transport Management, 16 (4), pp. 234-237, 2010.

[9] S. Hands, and B. Everitt, "A Monte Carlo study of the recovery of cluster structure in binary data by hierarchical clustering techniques," Multivariate Behavioral Research, 22 (2), pp. 235-243, 1987.

[10] J. F Hair Jr, M. Wolfinbarger, A. H. Money, P. Samouel, and M. J. Page, "Essentials of business research methods," Routledge, 2016.

[11] C. W. Hill, G. R. Jones, and M. A. Schilling, "Strategic management, theory," 12e. Cengage Learning, 2016.

[12] R. Collis, "What fliers would like-and get," International Herald Tribune, 16, 1998.

[13] N. Calisir, E. Basak, and F. Calisir, "Key drivers of passenger loyalty: A case of Frankfurt-Istanbul flights," Journal of Air Transport Management, 53, pp. 211-217, 2016.
[14] B. Gale, "Monitoring customer satisfaction and marketperceived quality, American Marketing Association worth Repeating Series," Number 922CSOI, American Marketing Association, Chicago, IL, 1992.

[15] R. Buzzell, B. Gale, "The PIMS Principle: Linking Strategy to Performance". FreePress, New York, 1987.

[16] C. K. W. Chow, "Customer satisfaction and service quality in the Chinese airline industry," Journal of Air Transport Management, 35, pp. 102-107, 2014

[17] C. Basfirinci, and A. Mitra, "A cross cultural investigation of airlines service quality through integration of Servqual and the Kano model," Journal of Air Transport Management, 42, pp. 239-248, 2015.

[18] R. Hussain, A. Al Nasser, and Y. K. Hussain, "Service quality and customer satisfaction of a UAE-based airline: An empirical investigation," Journal of Air Transport Management, 42, pp. 167-175, 2015.

[19] H. Jiang, and Y. Zhang, "An investigation of service quality, customer satisfaction and loyalty in China's airline market," Journal of air transport management, 57, pp. 80-88, 2016.

[20] F. Y. Chen, and Y. H. Chang, "Examining airline service quality from a process perspective," Journal of Air Transport Management, 11 (2), pp. 79-87, 2005.

[21] D. Gilbert, and R. K. Wong, "Passenger expectations and airline services: a Hong Kong based study," Tourism Management, 24 (5), pp. 519-532, 2003.

[22] A. Parasuraman, V. A. Zeithaml, and L. L. Berry, "Servqual: A multiple-item scale for measuring consumer perception of servcie quality," Journal of retailing, 64 (1), p. 12, 1988.

[23] J. J. Liou, and G. H. Tzeng, "A non-additive model for evaluating airline service quality," Journal of Air Transport Management, 13 (3), pp. 131-138, 2007.

[24] T. Jeeradist, N. Thawesaengskulthai, and T. Sangsuwan, "Using TRIZ to enhance passengers' perceptions of an airline's image through service quality and safety," Journal of Air Transport Management, 53, pp. 131-139, 2016.

[25] F. Pakdil, and Ö. Aydın, "Expectations and perceptions in airline services: An analysis using weighted SERVQUAL scores," Journal of Air Transport Management, 13 (4), pp. 229-237, 2007.

[26] J. W. Park, "Passenger perceptions of service quality: Korean and Australian case studies," Journal of Air Transport Management, 13 (4), pp. 238-242, 2007.

[27] R. Wang, Y. H. Lin, and M. L. Tseng, "Evaluation of customer perceptions on airline service quality in uncertainty". Procedia-Social and Behavioral Sciences, 25, pp. 419-437, 2011.

[28] B. D. Bowen, and D. E. Headley, "Airline Quality Rating 2015: The 25th year reporting airline performance," 2015.

[29] D. Gilbert, and R. K. Wong, "Passenger expectations and airline services: a Hong Kong based study," Tourism Management, 24 (5), pp. 519-532, 2003.

[30] H. Gupta, "Evaluating service quality of airline industry using hybrid best worst method and VIKOR," Journal of Air Transport Management, 2017. 
[31] M. Mellat-Parast, D. Golmohammadi, K. L. McFadden, and J. W. Miller, Linking business strategy to service failures and financial performance: Empirical evidence from the US domestic airline industry. Journal of Operations Management, 38, pp. 14-24, 2015.

[32] S. Perçin, "Evaluating airline service quality using a combined fuzzy decision-making approach," Journal of Air Transport Management, 2017.

[33] H. C. Wu, and C. C. Cheng, "A hierarchical model of service quality in the airline industry," Journal of Hospitality and Tourism Management, 20, pp. 13-22, 2013.
[34] J. O. Yimga, "Airline code-sharing and its effects on on-time performance". Journal of Air Transport Management, 58, pp. 76-90, 2017.

[35] L. Zhang, L. Zhang, P. Zhou, and D. Zhou, "A non-additive multiple criteria analysis method for evaluation of airline service quality," Journal of Air Transport Management, 47, pp. 154-161, 2015.

[36] D. R. Cooper, P. S Schindler, "Business research methods," $\left(12^{\text {th }}\right.$ ed), New York: McGraw-Hill Irwin, 2014. 